
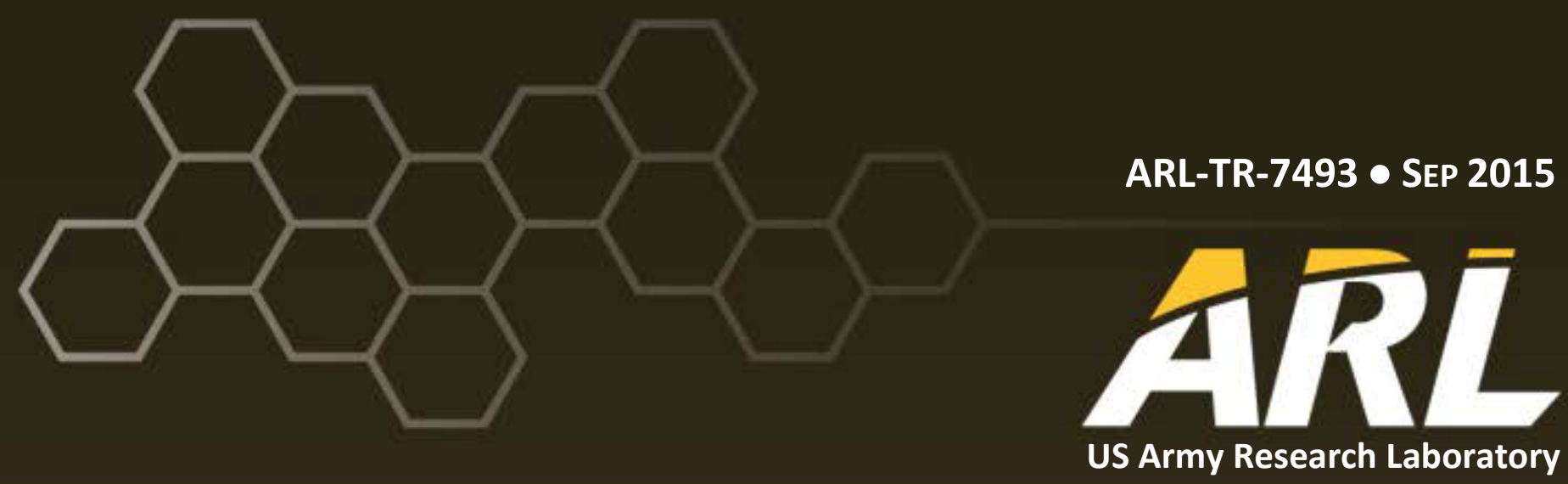

\title{
Experimental Setup for the Investigation of Superconducting Persistent Current
}

by Charles C Rong, Jason D Miller, George A Levin, and Paul N Barnes 


\section{NOTICES}

\section{Disclaimers}

The findings in this report are not to be construed as an official Department of the Army position unless so designated by other authorized documents.

Citation of manufacturer's or trade names does not constitute an official endorsement or approval of the use thereof.

Destroy this report when it is no longer needed. Do not return it to the originator. 


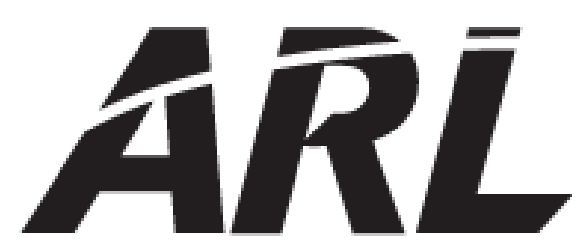

US Army Research Laboratory

\section{Experimental Setup for the Investigation of Superconducting Persistent Current}

by Charles $\mathrm{C}$ Rong and Paul $\mathrm{N}$ Barnes

Sensors and Electron Devices Directorate, ARL

Jason D Miller

Naval Surface Warfare Center, Carderock Division

George A Levin

Florida Institute of Technology 


\section{REPORT DOCUMENTATION PAGE}

Public reporting burden for this collection of information is estimated to average 1 hour per response, including the time for reviewing instructions, searching existing data sources, gathering and maintaining the data needed, and completing and reviewing the collection information Send comments regarding this burden estimate or any other aspect of this collection of information, including suggestions for reducing the burden, to Department of Defense, Washington Headquarters Services, Directorate for Information Operations and Reports (0704-0188), 1215 Jefferson Davis Highway, Suite 1204, Arlington, VA 22202-4302 Respondents should be aware that notwithstanding any other provision of law, no person shall be subject to any penalty for failing to comply with a collection of information if it does not display a currently valid OMB control number

PLEASE DO NOT RETURN YOUR FORM TO THE ABOVE ADDRESS.

\begin{tabular}{l|l} 
1. REPORT DATE (DD-MM-YYYY) & $\begin{array}{l}\text { 2. REPORT TYPE } \\
\text { Sep } 2015\end{array}$ \\
Final
\end{tabular}
$\begin{aligned} & \text { 4. TITLE AND SUBTITLE } \\
& \text { Experimental Setup for the Investigation of Superconducting Persistent Current }\end{aligned}$

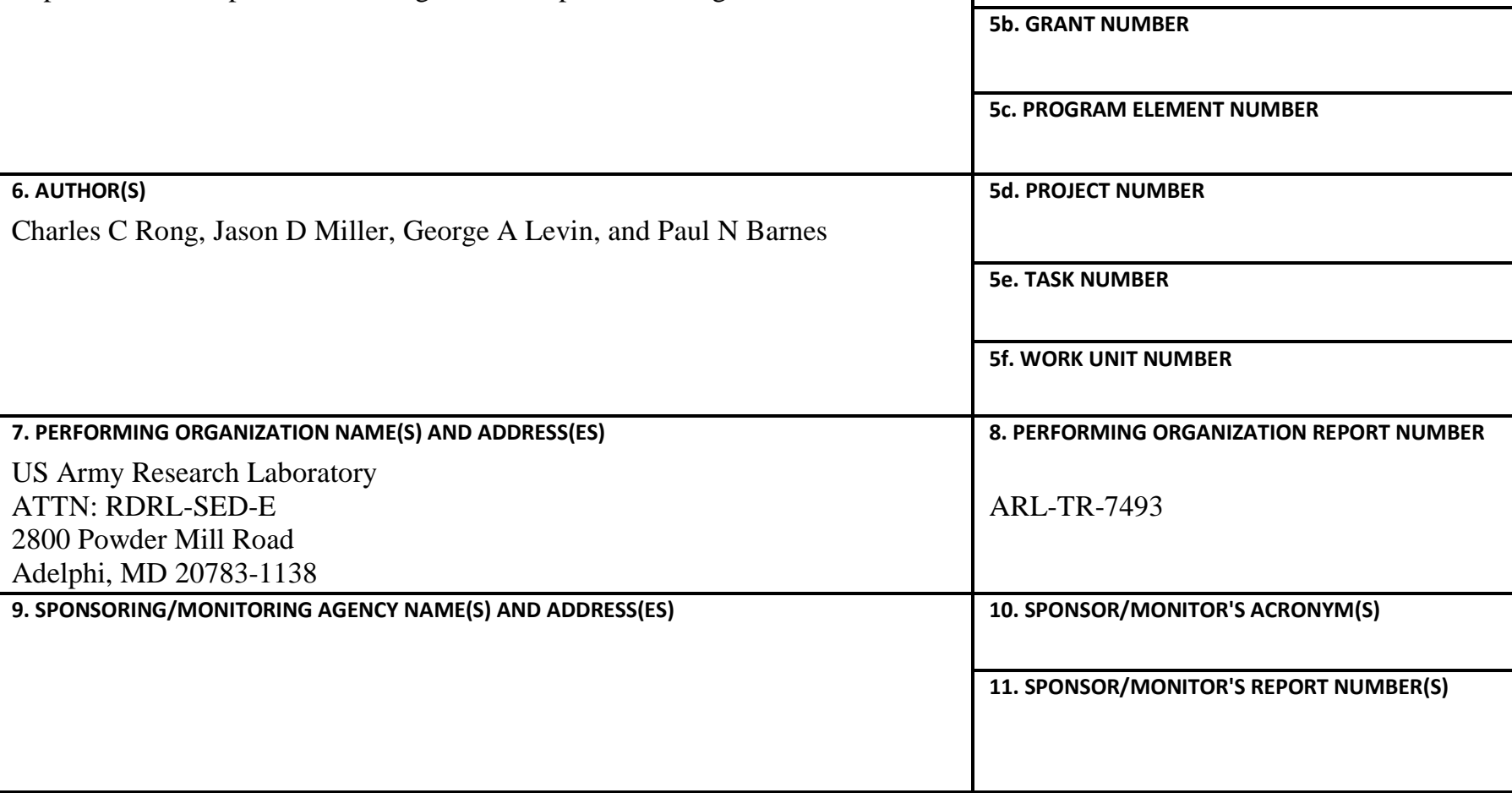

\section{DISTRIBUTION/AVAILABILITY STATEMENT}

Approved for public release; distribution is unlimited.

\section{SUPPLEMENTARY NOTES}

\section{ABSTRACT}

We report on a recent experimental setup for the investigation of the relaxation rate of the persistent current in an assembly of closed superconducting loops made out of currently manufactured coated conductors. This report describes how to prepare closed superconducting loops made with commercial coated conductors for the assembly, mount the assembly in a cryostat, and operate the experimental setup for data acquisition. This documentation is intended to support future investigations of coated conductors in either tape or wire form or for bulk superconductors in an appropriate form of closed circuit. One of the advantages of this experimental setup is the ability to study superconducting current characteristics at cryo-temperatures in magnetic field at time scale of seconds to hours.

\section{SUBJECT TERMS}

persistent current, 2G HTS, coated conductor, relaxation rate, BEBCO

\begin{tabular}{|l|l|l|l|l|l|}
\hline \multicolumn{2}{|l|}{ 16. SECURITY CLASSIFICATION OF: } & $\begin{array}{l}\text { 17. LIMITATION } \\
\text { OF } \\
\text { ABSTRACT }\end{array}$ & $\begin{array}{l}\text { 18. NUMBER } \\
\text { OF } \\
\text { PAGES }\end{array}$ & $\begin{array}{l}\text { 19a. NAME OF RESPONSIBLE PERSON } \\
\text { Charles C Rong }\end{array}$ \\
\cline { 1 - 2 } $\begin{array}{l}\text { a. REPORT } \\
\text { Unclassified }\end{array}$ & $\begin{array}{l}\text { b. ABSTRACT } \\
\text { Unclassified }\end{array}$ & $\begin{array}{l}\text { c. THIS PAGE } \\
\text { Unclassified }\end{array}$ & UU & 32 & $\begin{array}{l}\text { 19b. TELEPHONE NUMBER (Include area code) } \\
301-394-0286\end{array}$ \\
\hline
\end{tabular}




\section{Contents}

List of Figures iv

List of Tables $\mathbf{v}$

Acknowledgments vii

$\begin{array}{ll}\text { 1. Introduction } & 1\end{array}$

2. Experimental 1

$\begin{array}{ll}2.1 \text { Superconducting Tape } & 1\end{array}$

2.1.1 Relationship of Sample Length and the Curvature Radius 1

2.1.2 Milling Setup 5

$\begin{array}{lll}2.1 .3 & \text { Silver Coating } & 7\end{array}$

$\begin{array}{lll}2.1 .4 & \text { Parylene Coating } & 7\end{array}$

2.2 Superconducting Coil Assembly 8

2.3 Measurement Setup 9

2.3.1 Gaussmeter 9

2.3.2 Connection of Hall Sensor through HMCBL cable to Gaussmeter 9

2.3.3 Gasometer and the HMCBL Cable Setup 10

2.3.4 DC Power Supply 11

2.3.5 Temperature Sensor (Attachment, Calibration) 11

2.3.6 Magnet and Cryostat 11

$\begin{array}{ll}\text { 3. } & \text { Representative Results } \\ \end{array}$

$\begin{array}{ll}\text { 4. Discussion } & 18\end{array}$

$\begin{array}{ll}\text { 5. Conclusion } & 19\end{array}$

$\begin{array}{ll}\text { 6. } & \text { References } \\ \end{array}$

$\begin{array}{ll}\text { Distribution List } & 22\end{array}$ 


\section{List of Figures}

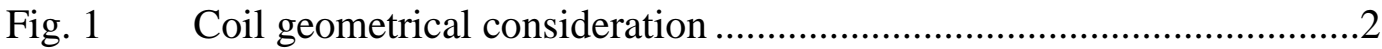

Fig. 2 Tape size (upper) and coil assembly dimensions.................................4

Fig. 3 Tape end portion ...........................................................................

Fig. 4 Milling setup ........................................................................6

Fig. 5 Size of the tape for cutting.........................................................6

Fig. 6 Milled tape samples for superconducting coil assembly ......................7

Fig. 7 Photo of the end portion of the slit milled on the tape and coated with silver and then parylene polymer. Darker color indicates the portion that was milled away from the tape as the slit. ..................................7

Fig. 8 The coil assembly holder part dimensions ........................................8

Fig. 9 Superconducting coil assembly made by tapes with a co-axial solenoid of copper wires placed inside........................................................8

Fig. 10 The Lakeshore DA-15 connector terminal for its HMCBL cable .........9

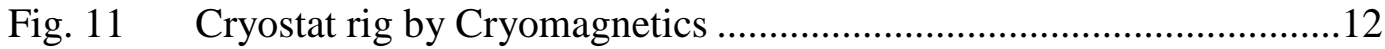

Fig. 12 Drawings of cryostat magnet dimensions (left) and sample chamber

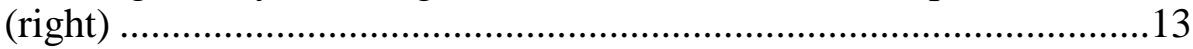

Fig. 13 Sample chamber and lid dimensions..............................................13

Fig. 14 Drawing of the sample chamber .....................................................14

Fig. 15 Drawing of the sample chamber lid assembly ..................................14

Fig. 16 Drawing of the flange to hold the superconducting coil assembly......15

Fig. 17 Drawing of the bottom plate to hold the superconducting coil assembly.

Fig. 18 Drawing of the fixture of the bottom plate and flange made of G10 materials with 4 rods attached to the bottom plate and the chamber lid. The flange is connected to the chamber lid with three G10 rods. The superconducting coil assembly is placed on the bottom plate.

Fig. 19 The location of the Hall sensor inside the superconducting coil assembly

Fig. 20 Calibration of superconducting coil assembly electric current and magnetic field reading. The closed loop of the tape was cut at 1 end of the tape resulting in terminals that were soldered to 2 pieces of copper wire that were connected to the external power supply. 16

Fig. 21 The superconducting coil assembly placed on the bottom plate by the holder parts with the Hall sensor in the center of the coil assembly. The location is basically the same as Fig. 18. Toward to the left end of the loop, a temperature sensor was attached to the loop. 
Fig. 22 Field readings in gauss at constant current in ampere at room temperature with the opened tape coil connected the leads of power

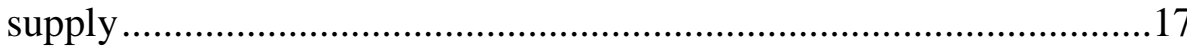

Fig. 23 Relationship of the field and electric current in the opened coil from the data in Fig. 22........................................................................18

\section{List of Tables}

Table 1 RE123 tapes by SuperPower.......................................................... 
INTENTIONALLY LEFT BLANK. 


\section{Acknowledgments}

We appreciate our US Army Research Laboratory (ARL) colleagues for their technical assistance, Nicolas Strand with the silver coating and Dave Lunking with the parylene coating.

Note that Jason D. Miller is with Naval Surface Warfare Center Carderock Division in Philadelphia. George A. Levin is with Florida Institute of Technology. 
INTENTIONALLY LEFT BLANK. 


\section{Introduction}

Second-generation, high-temperature, coated superconductors, such as yttrium barium copper oxide $\left(\mathrm{Y}_{1} \mathrm{Ba}_{2} \mathrm{Cu}_{3} \mathrm{O}_{7-\delta}\right.$, or $\mathrm{REBCO}$, or $\left.\mathrm{RE} 123\right)$, are manufactured by several companies and are available in reasonable lengths ${ }^{1-3}$ with high performance through flux pinning enhancement. ${ }^{4-6}$ These conductors, able to carry high currents in background fields of 1.5-3 Tesla even at a temperature of $77 \mathrm{~K}$, open new possibilities for superconducting magnetic energy storage (SMES), as well as the magnetic resonance imaging (MRI) systems due to their much-reduced cooling and vacuum cryostat requirements. The use of high-temperature superconducting (HTS) wires has the potential to lower the cost of such systems, making them smaller and more robust due to reduced cryogenic needs, which are benefits-in addition to their superconducting advantage-desirable in energy storage with magnets ${ }^{7}$ and in power source applications. ${ }^{8}$

In order to push the high-temperature superconductors to a more mature degree, new knowledge and deeper understanding of the physical phenomena and behavior of these state-of-the-art, industrially manufactured conductors will provide useful technical input to the engineering and design effort of component and device applications. Although there are other substantial issues to be overcome with respect to HTS SMES application, which requires persistent superconducting current with no or minimum energy dissipation, we focus our effort on only one of the issues, namely, persistent current behavior in a true closed loop without any physical non-superconductive joint. ${ }^{9}$ The investigations of persistent current characteristics have been reported elsewhere, ${ }^{10,11}$ and this report documents only the part of the research effort in setting up the experiments for the investigation, which is generally not described in great details in regular journal publications.

\section{Experimental}

\subsection{Superconducting Tape}

\subsubsection{Relationship of Sample Length and the Curvature Radius}

In coil geometry, the relationship between the length of the sample and the curvature radius is determined by a condition (rather arbitrary in our case) that all parts of the curved tape have the same curvature radius $\mathrm{R}$ (Fig. 1). Some sections will be concave, others will be convex, but all will have the same radius. It is important that the parts at the ends of the tape (of length $\Delta$ ) are straight in order to avoid stress that may cause fractures to propagate along the centerline. 


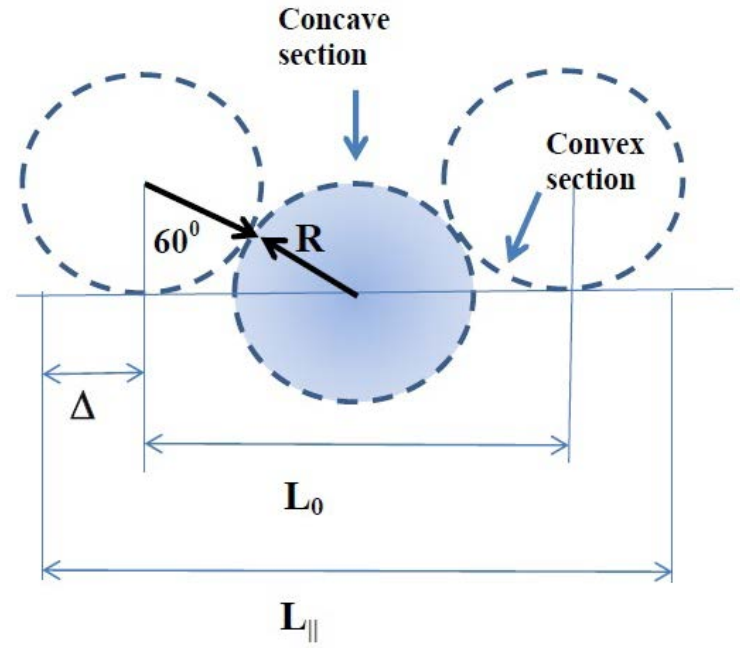

Fig. 1 Coil geometrical consideration

Below are idealized estimates. The length of the curved section is

$$
L-2 \Delta=R \theta_{0}+2 R \theta_{1},
$$

where $\theta_{1}=60^{\circ}$ is indicated in the Fig. 1 and $\theta_{0}=120^{\circ}$ is the arc of the concave section. Thus,

$$
L-2 \Delta=\frac{4 \pi}{3} R .
$$

The length $\mathrm{L}_{0}$ is given by

$$
L_{0}=4 R \sin 60^{\circ}=2 \sqrt{3} R \text {. }
$$

The total length of the loop

$$
L_{\|}=L_{0}+2 \Delta=2 \sqrt{3} R+2 \Delta .
$$

Taking into account Eq. 2, the maximum size of the loop is determined by the length of the sample $L$ and the length of the uncut ends $\Delta$,

$$
L_{\|}=\frac{3 \sqrt{3}}{2 \pi}(L-2 \Delta)+2 \Delta=\frac{3 \sqrt{3}}{2 \pi} L+2 \Delta\left(1-\frac{3 \sqrt{3}}{2 \pi}\right) .
$$

Considering that

$$
\frac{3 \sqrt{3}}{2 \pi} \approx 0.83
$$


we get

$$
L_{\|}=0.83 L+0.34 \Delta
$$

The maximum size $L \|$ determines the size of the cryostat, Fig. 1 . In the perpendicular direction the size of the loop is $2 R$, smaller than $L \|$.

The following are examples.

In the paper published in 2008, ${ }^{9}$ the length of the samples $L=15 \mathrm{~cm}$ and $\Delta=1.3 \mathrm{~cm}$. According to Eq. 2, the radius of the coil former was chosen to be $R \approx 3 \mathrm{~cm}$. The total length of the loop

$$
L_{\|}=0.83 L+0.34 \Delta=12.9 \mathrm{~cm}
$$

In another example, the length of the sample previously used in experiments ${ }^{10}$ was $L=11 \mathrm{~cm}$ with $\Delta=1 \mathrm{~cm}$. Then, the maximum radius of the coil former, Eq. 2,

$$
R=2.15 \mathrm{~cm}
$$

and the maximum size, Eq. 7,

$$
L_{\|} \approx 9.5 \mathrm{~cm}
$$

Coated conductors seem to tolerate the curvature radius of $2 \mathrm{~cm}$. On the other hand, one can start with the dimensions of the cryostat, such as $L \|$; determine the necessary length $\Delta$; and then determine what the length of the individual sample $L$ should be.

The value of $\Delta$ is not known because it is determined by the anisotropy of the critical current, which nobody seems to care to measure. So far, we followed the rule of thumb that $\Delta$ should be at least twice the width of the conductor. For a 12 -mm-wide coated conductor with the slit $1 \mathrm{~mm}$ wide, we assume that $\Delta=13-15 \mathrm{~mm}$ will be sufficient and these parts of the loop will not be the bottlenecks for the persistent current.

Returning to the NRL cryostat, we assume that the total length $L \| \approx 9.5 \mathrm{~cm}$ must be the same. If we take $\Delta=15 \mathrm{~mm}$, we get from Eq. 7

$$
L=\frac{L_{\|}-0.34 \Delta}{0.83} \approx 10.8 \mathrm{~cm}, R=\frac{3}{4 \pi}(L-2 \Delta) \approx 1.86 \mathrm{~cm} \text {. }
$$

This is very close to what was used with 4-mm conductors, but the radius of curvature is substantially tighter, which may be a cause for concern. 
For more accurate estimates, we need to take into account that the straight sections of the loop must be slightly longer than $\Delta$, as shown in Fig. 2. Otherwise, the stress of bending 2 halves of the conductor in the opposite directions will create and propagate a crack in the film. This means that in Eqs. 2-7 the value of $\Delta$ has to be replaced by $\Delta_{1}>\Delta$ (Fig. 2). Let us take in the last example $\Delta=15 \mathrm{~mm}$, but $\Delta_{1}=18 \mathrm{~mm}$. Then, for $L \| \approx 9.5 \mathrm{~cm}$ we get

$$
L=\frac{L_{\|}-0.34 \Delta^{\prime}}{0.83} \approx 10.7 \mathrm{~cm}
$$

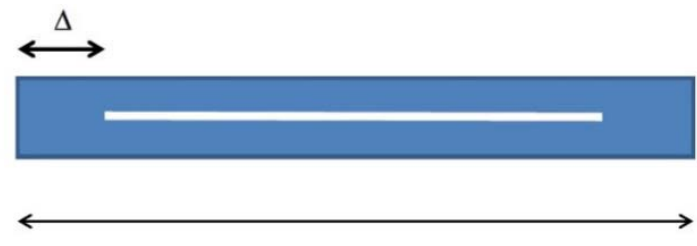

$\mathbf{L}$

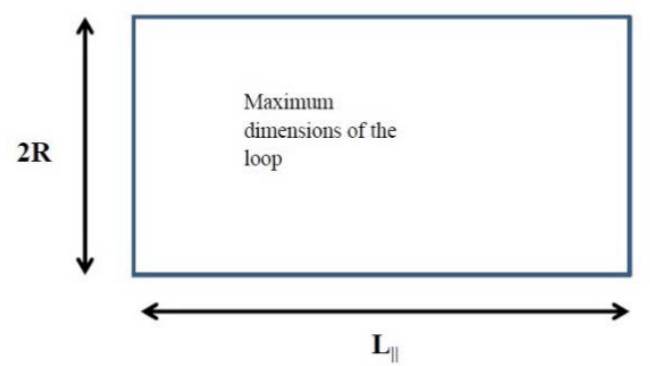

Fig. 2 Tape size (upper) and coil assembly dimensions

Not a big difference. However, the curvature radius in this case is

$$
R=\frac{3}{4 \pi}\left(L-2 \Delta^{\prime}\right) \approx 1.7 \mathrm{~cm}
$$

This is somewhat too tight. One should consider whether the assumed maximum size of $L \| \approx 9.5 \mathrm{~cm}$ is too small and the cryostat allows a greater maximum size of the loop. Figure 3 shows the tape end portion. 


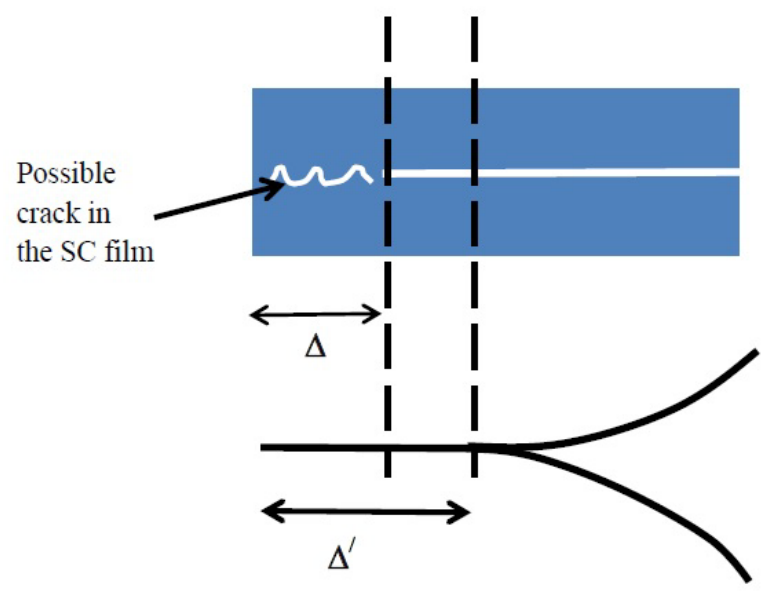

Fig. 3 Tape end portion

\subsubsection{Milling Setup}

The closed loops in this investigation were made with RE123 tape manufactured by SuperPower Inc. Three tape samples were ordered, as shown in Table 1 identified by product number and the corresponding critical current at $77 \mathrm{~K}$. Note that AP indicates Advanced Pinning formulation while CF indicates Cable Formulation. The critical temperature of these tapes are at $90 \mathrm{~K}$. Figure 4 shows the milling setup.

Table 1 RE123 tapes by SuperPower

\begin{tabular}{cc}
\hline Product Number & $\begin{array}{c}\text { Critical Current Ic } \\
\text { (77 K) }\end{array}$ \\
\hline M4-195-2 SF12050-AP & $420 \mathrm{~A}$ \\
M4-107-1 SF12050-AP & 286 A \\
M4-244-1 SF12050-CF & $562 \mathrm{~A}$ \\
\hline
\end{tabular}




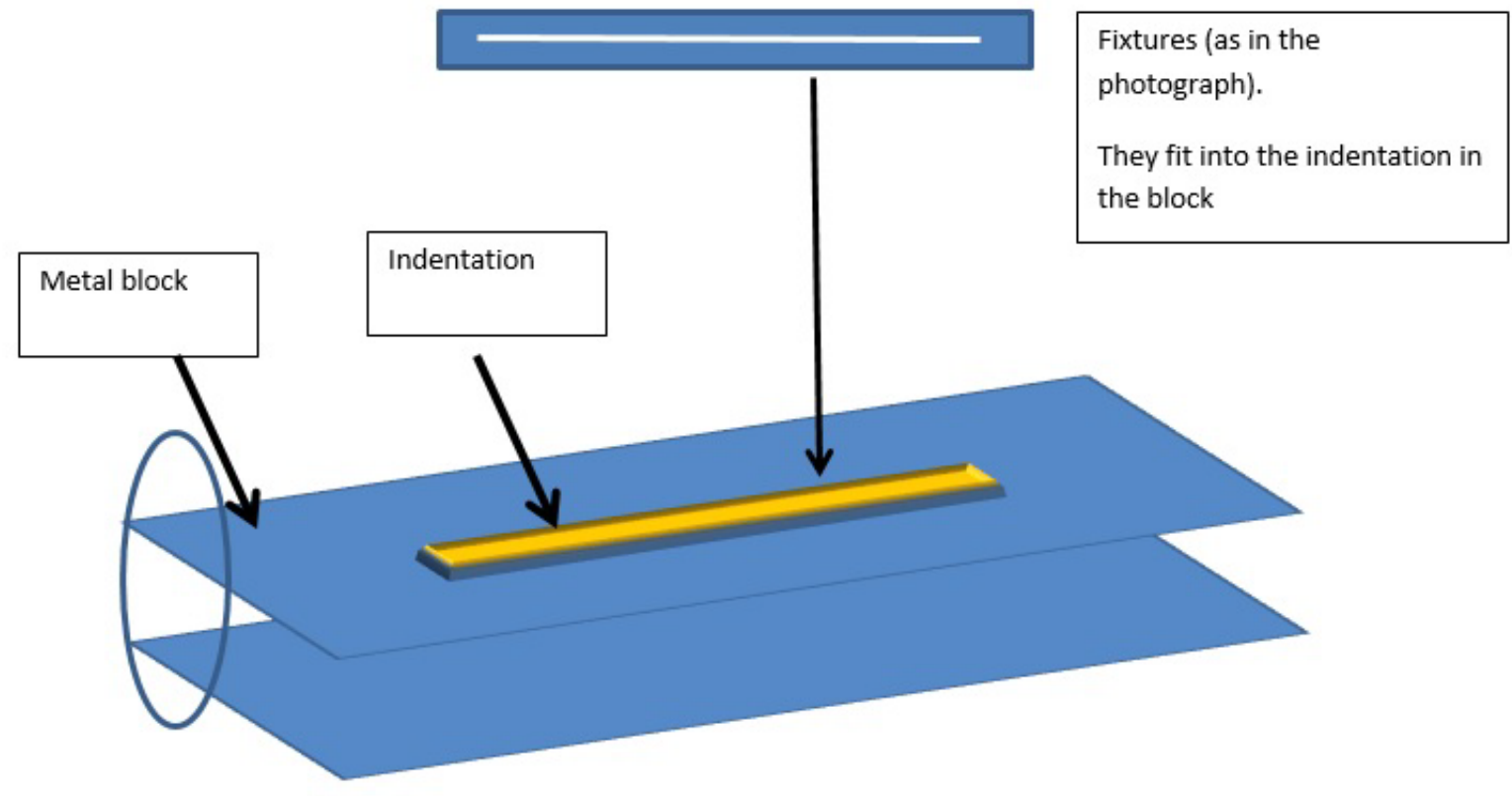

Coated conductor is placed between two fixture and this assembly is placed into the indentation inside the metal block and fixed at the end preventing its movement.

Fig. 4 Milling setup

The coated conductor is $12 \mathrm{~mm}$ in width and was cut in pieces of $100 \mathrm{~mm}$ in length, as shown in Fig. 5, and the closed loop by the cut tape is shown in Fig. 6.

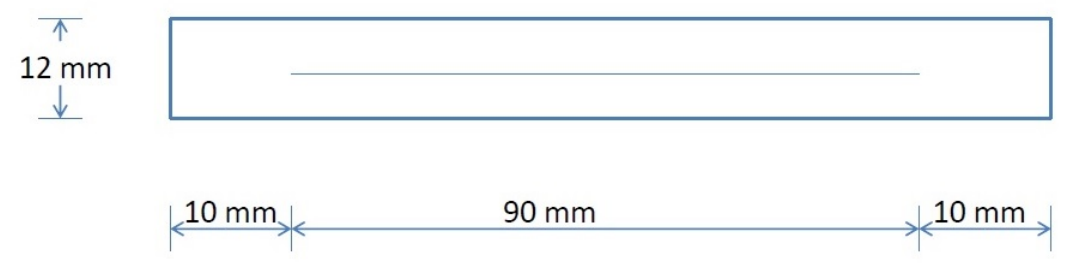

Fig. 5 Size of the tape for cutting 


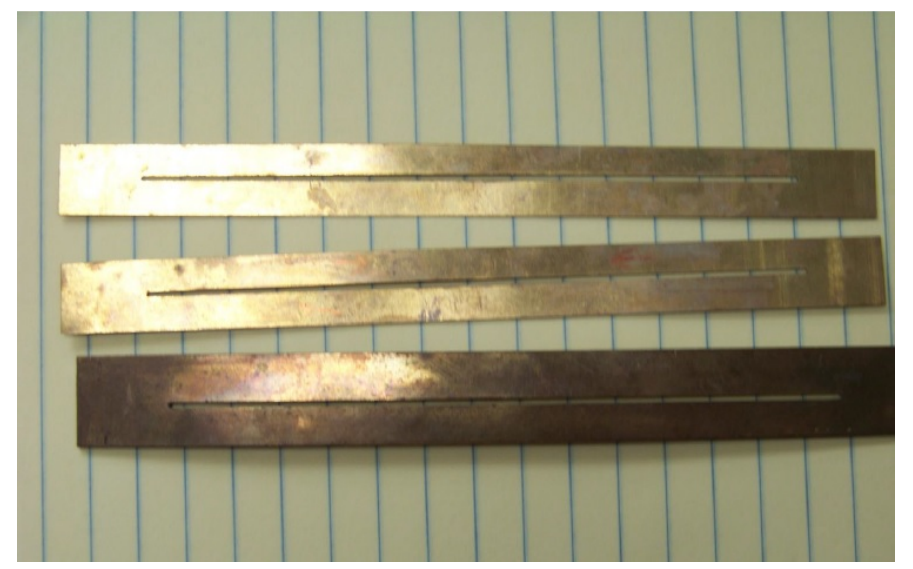

Fig. 6 Milled tape samples for superconducting coil assembly

\subsubsection{Silver Coating}

After the tapes were milled, the tape samples were coated with a layer of silver of $5 \sim 10 \mu \mathrm{m}$ by thermal evaporation method (with a PVD 75 Thermal Evaporator by Kurt J Lesker Company) so that the cross section of the RE123 layer (exposed portion) that is perpendicular to the surface of the tape is protected by silver from losing oxygen atom in the structure of RE123.

\subsubsection{Parylene Coating}

In order to further protect the RE123 layer from contacting moisture, after the silver coating, a layer of polymerized parylene coating ( $25 \mu \mathrm{m}$ thickness, using $42 \mathrm{~g}$ of parylene powder) was made on the tape samples with a SCS Labcoter 2 (PDS 2010) Parylene Deposition System by Specialty Coating Systems (Fig 7).

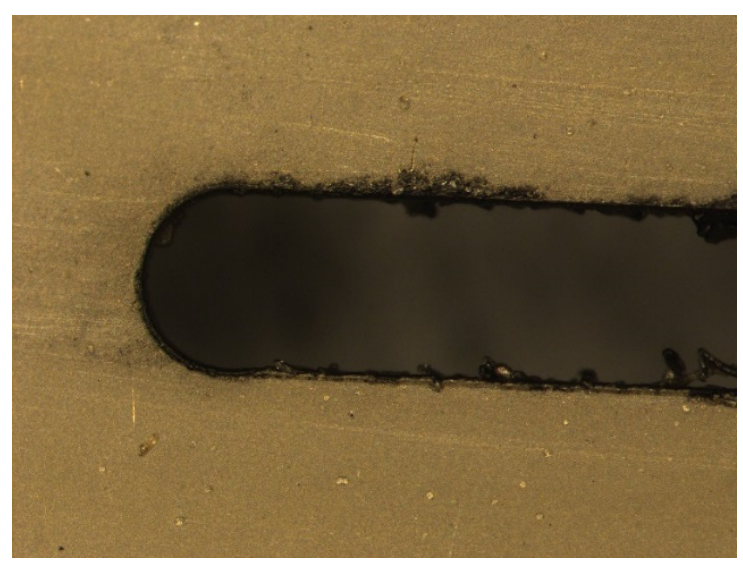

Fig. 7 Photo of the end portion of the slit milled on the tape and coated with silver and then parylene polymer. Darker color indicates the portion that was milled away from the tape as the slit. 


\subsection{Superconducting Coil Assembly}

Figures 8 and 9 show the dimensions of Teflon holders and the superconductor coil assembly originally designed, along with a separate copper coil that is used to generate an external magnetic field to induce a super current in the superconducting coil. As a matter of fact, in those experiments ${ }^{10,11}$ carried out at the Naval facility, a built-in magnet was actually used instead of the copper coil in order to accurately control the magnetic field strength and correlate the filed strength with superconducting current level.
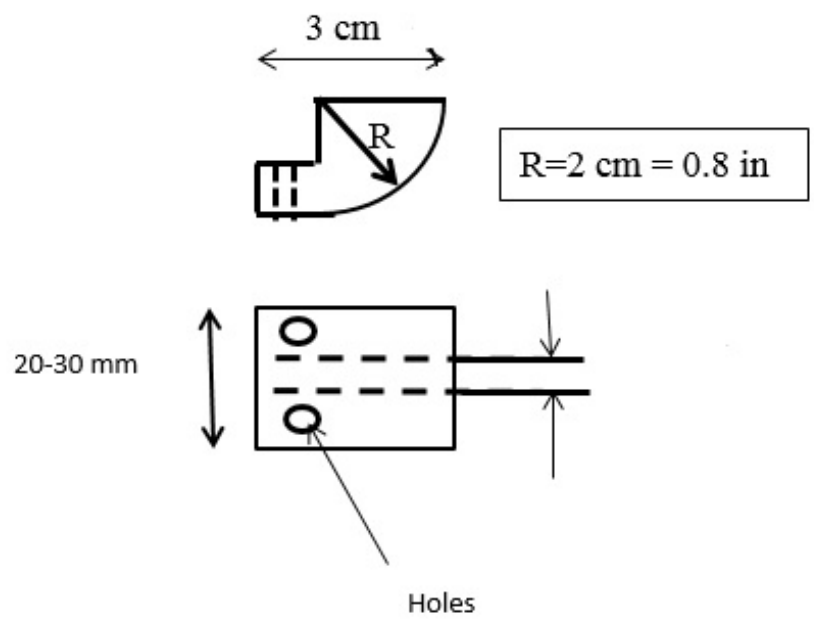

Fig. 8 The coil assembly holder part dimensions

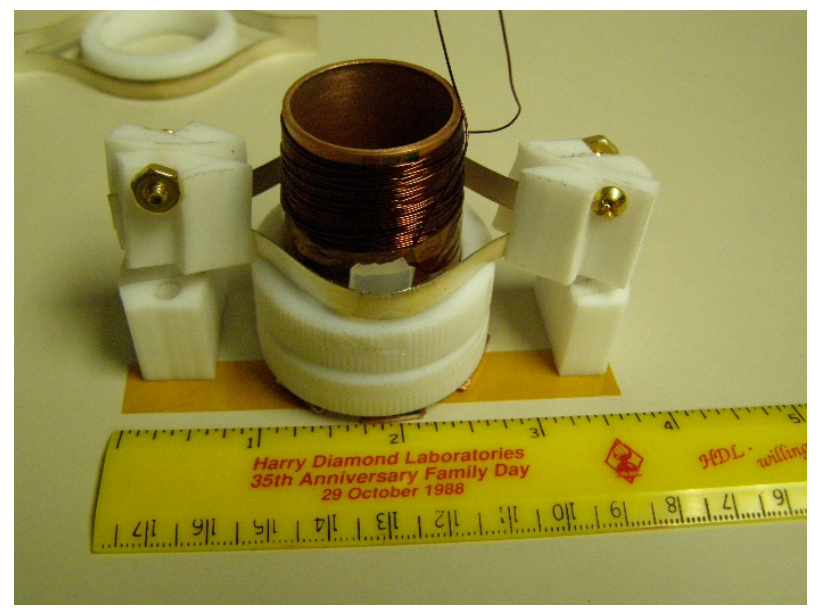

Fig. 9 Superconducting coil assembly made by tapes with a co-axial solenoid of copper wires placed inside 


\subsection{Measurement Setup}

\subsubsection{Gaussmeter}

A Lakeshore gaussmeter (Model 475) was used in the measurement. An indium arsenide (InAs) type Hall generator sensor (HGCA-3020, with a mean loaded sensitivity of $0.720 \mathrm{mV} / \mathrm{kG}$ and a zero field offset voltage of $-6.0 \mu \mathrm{V}$, series number 53950) was installed in the center of the coil assembly. There are 4 colored leads from the sensor, and 4 corresponding colored leads from a HMCBL interface cable with a DA-15 Connector. The HMCBL interface cable connects to the Hall sensor by the corresponding leads on one end and by the DA-15 connector to the gaussmeter on the other. Specifications of the connections provided by Lakeshore are shown in Fig 10. The Hall sensor was calibrated at room temperature using the Lakeshore calibration device. Once experiments were in process, the Hall sensor can be always calibrated (set to zero reading) inside the cryostat. There was not much difference observed between the calibrated zero at room temperature and the environment values within the cryostat without any current running in the superconducting assembly loops at cryogenic temperatures.

\begin{tabular}{|c|c|c|c|c|}
\hline & Pin & Description & Pin & Description \\
\hline & 1 & INPUT + & 9 & INPUT - \\
\hline & 2 & NC & 10 & NC \\
\hline & 3 & NC & 11 & GND 1 \\
\hline & 4 & ITEMP + & 12 & Vcc \\
\hline$\bigcirc^{1} \bigcirc^{2} \bigcirc^{3} \bigcirc^{4} O^{5} \bigcirc^{6} \bigcirc^{7} 0^{7} 0^{8}$ & 5 & ITEMP - & 13 & A/D CLK \\
\hline & $\begin{array}{l}6 \\
7\end{array}$ & $\begin{array}{l}\text { NC } \\
\text { NC }\end{array}$ & $\begin{array}{l}14 \\
15\end{array}$ & $\begin{array}{l}\text { EE-DATA } \\
I_{C-}-\end{array}$ \\
\hline $\begin{array}{lllllll}9 & 10 & 11 & 12 & 13 & 14 & 15\end{array}$ & 8 & $\mathrm{IC}^{+}$ & & \\
\hline
\end{tabular}

Fig. 10 The Lakeshore DA-15 connector terminal for its HMCBL cable

\subsubsection{Connection of Hall Sensor through HMCBL cable to Gaussmeter}

At Hall sensor end, there are the following leads: going from the current to the sensor, a black wire/lead (-) and red wire/lead (+), and to the voltage from the sensor, a blue wire/lead $(+)$ and yellow wire/leads $(-)$.

The 4 leads from the Hall sensor should be connected to the DA-15 connector as follows: black wire/lead $(-)$ to $15\left(\mathrm{I}_{\mathrm{c}}-\right)$; red wire/lead $(+)$ to $8\left(\mathrm{I}_{\mathrm{c}}+\right)$; blue wire/lead (+) to 1 (voltage input + ); and yellow wire/leads (-) to 9 (voltage input -).

Care should be taken to make sure all wires are connected correctly in accordance with the specifications in order for proper measurements. Please refer to the product instructions and guidelines provided by Lakeshore Cryogenics. 


\subsubsection{Gasometer and the HMCBL Cable Setup}

Once the Hall sensor is connected to the gaussmeter, certain parameters should be entered initially to the gaussmeter.

If the gaussmeter detects the presence of an HMCBL cable with no sensitivity information (a new, blank cable), the instrument will display a message indicating "Invalid Probe." Press the Enter button to clear the message. The instrument will jump directly to the probe setup screens beginning with the probe serial number entry screen. If the instrument is already displaying a reading, the probe information may be changed.

To configure the HMCBL cable, press and hold the Probe key for approximately $4 \mathrm{~s}$ and wait for a prompt for selecting the programming method. Use the up and down arrow key to select the MCBL Program (user programmable cables). Press Enter to accept the new selection and continue to the next setting screen. Press Escape to cancel the selection and return to the normal display. If an invalid HMCBL cable is attached (for instance, a fully calibrated Lakeshore probe) and the MCBL program is attempted, the following message will appear for approximately 5 s. "Invalid MCBL cable".

If a valid HMCBL cable is attached, the next MCBL Program screen appears as a prompt for serial number, which was 53950 in this experimental research. Press Enter to accept the new value and continue to the next setting screen. If desired, press Escape to restart the setting sequence and enter a new value. Press Escape again to cancel the sequence and return to the normal display.

The next MCBL program screen appears as a prompt for entering the Hall sensor control current (note that the current selected can alter the sensitivity as noted below). Most Lakeshore Hall sensors are specified at $100 \mathrm{~mA}$, though a current other than $100 \mathrm{~mA}$ can be used. ${ }^{12}$

The next MCBL program screen appears as a prompt for entering the nominal sensitivity in $\mathrm{mV} / \mathrm{kG}$. This sensitivity is based on the control current to be used $(1,10$, or $100 \mathrm{~mA})$. Note that the sensitivity of Lakeshore Hall sensors is specified as $100 \mathrm{~mA}$ in most cases. (For instance, if a current of $10 \mathrm{~mA}$ is used for a Hall sensor with a sensitivity specified at $100 \mathrm{~mA}$, the proper sensitivity to enter is approximately 0.1 that of the $100-\mathrm{mA}$ value.)

Use the data entry keys to enter the nominal sensitivity value from 1 of the following ranges: between 0.550 and $1.100 \mathrm{mV} / \mathrm{kG}$; between 5.500 and $11.000 \mathrm{mV} / \mathrm{kG}$; and between 550 and $1100 \mathrm{mV} / \mathrm{kG}$ (when using a control current of $100 \mathrm{~mA}$ ). Press Enter to accept the new value and return to the normal display. 
If desired, press Escape to restart the setting sequence and enter a new value. Press Escape again to cancel the sequence and return to the normal display.

The gaussmeter will adjust the available ranges based on the values entered for the current and sensitivity.

Note: Using a sensitivity outside the above 100-mA ranges (or their equivalent 10- and 1-mA ranges) may cause reduced performance. Values near, but lower than, the minimum of the ranges shown above will reduce resolution. Values near, but above, the maximum of the ranges shown above may cause an instrument overload "OL” condition before full-scale range is reached. Hence, using Hall sensors with sensitivities outside the above-indicated ranges is discouraged.

All of the above entries will be stored in the HMCBL cable PROM (located in the connector). Thus, anytime the cable/Hall sensor combination is used, the Lakeshore gaussmeter will recognize the stored parameters, and operation may proceed. The HMCBL cables may be reprogrammed for other Hall sensors as needed.

\subsubsection{Power Supply}

An Agilent DC power supply (Model E 3633A) was used in the experiment with 2 voltage/current ranges: $0-8 \mathrm{~V}, 20 \mathrm{~A}$ and $0-20 \mathrm{~V}, 10 \mathrm{~A}$. The superconducting current and the corresponding magnetic field correlation was established by simultaneous measurement of current reading from the power supply and the field reading by the gaussmeter. It is a linear relationship, see Section 3 .

\subsubsection{Temperature Sensor (Attachment, Calibration)}

There were 2 temperature sensors directly attached to the superconducting tape sample by GE Varnish GE 7031, a non-permanent adhesive for cryogenic temperature applications with good thermal conductivity. The temperature sensors were calibrated at $0{ }^{\circ} \mathrm{C}$ (ice water) and $77 \mathrm{~K}$ (liquid nitrogen). The temperature data were acquired simultaneously with magnetic field data in the experiments.

\subsubsection{Magnet and Cryostat}

A 5-Tesla Cryomagnetics low-temperature superconducting magnet cryostat was used to induce supercurrent in the closed loops and maintain the temperature below $77 \mathrm{~K}$. Figure 11 is the photo of the cryostat. Figures $12-18$ are drawings with dimensions of the inside chamber and the G10 parts to make the fixture where the Hall sensor and superconducting loops should be mounted. Figures 19-21 are photos of the locations of the loops and the Hall sensor. The cryo-cooling system has 4 cold heads with individual valves to control the helium gas from each cold head to cryostat. Each cold head has its individual compressor. The 4 cold heads 
and the cryostat are connected as a whole system, and the cooling capacity can be adjusted by using $1,2,3$, or all 4 cold heads with the corresponding valve and compressor turned on. No matter in what settings, it takes from a few hours to overnight to establish an equilibrated and stable cryostat temperature, usually with cold head(s) at even lower temperatures than that of cryostat.

Operation of the magnet control is straightforward. The field cool experiment was conducted by turning on the magnet to the desired field level, and then starting the cooling of the cryostat. Once the temperature was stabilized, by turning off the magnet to zero level, we started the data acquisition of the field reading, temperature reading, and time.

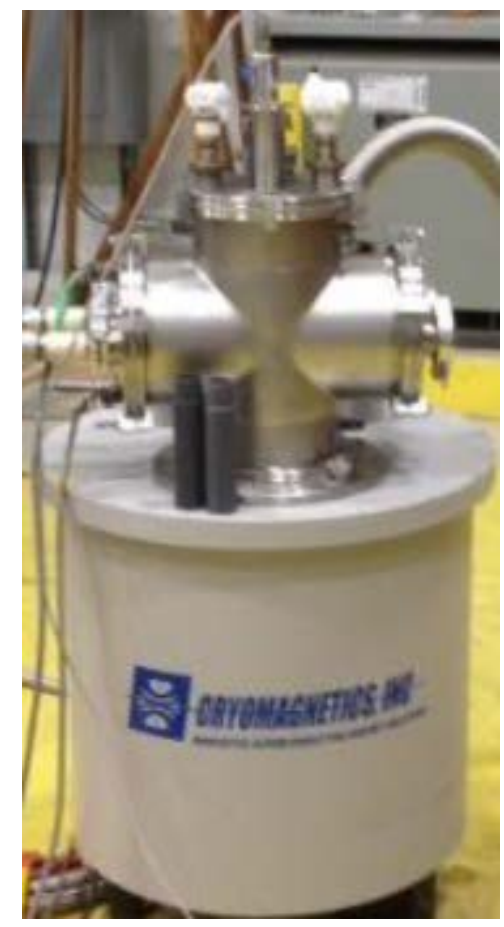

Fig. 11 Cryostat rig by Cryomagnetics 

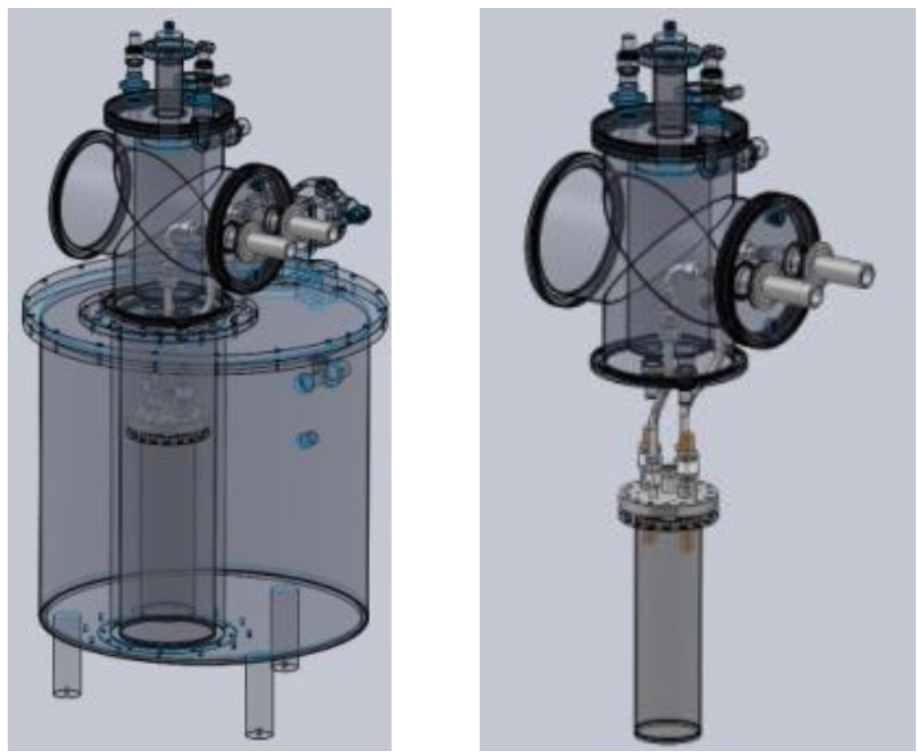

Fig. 12 Drawings of cryostat magnet dimensions (left) and sample chamber (right)

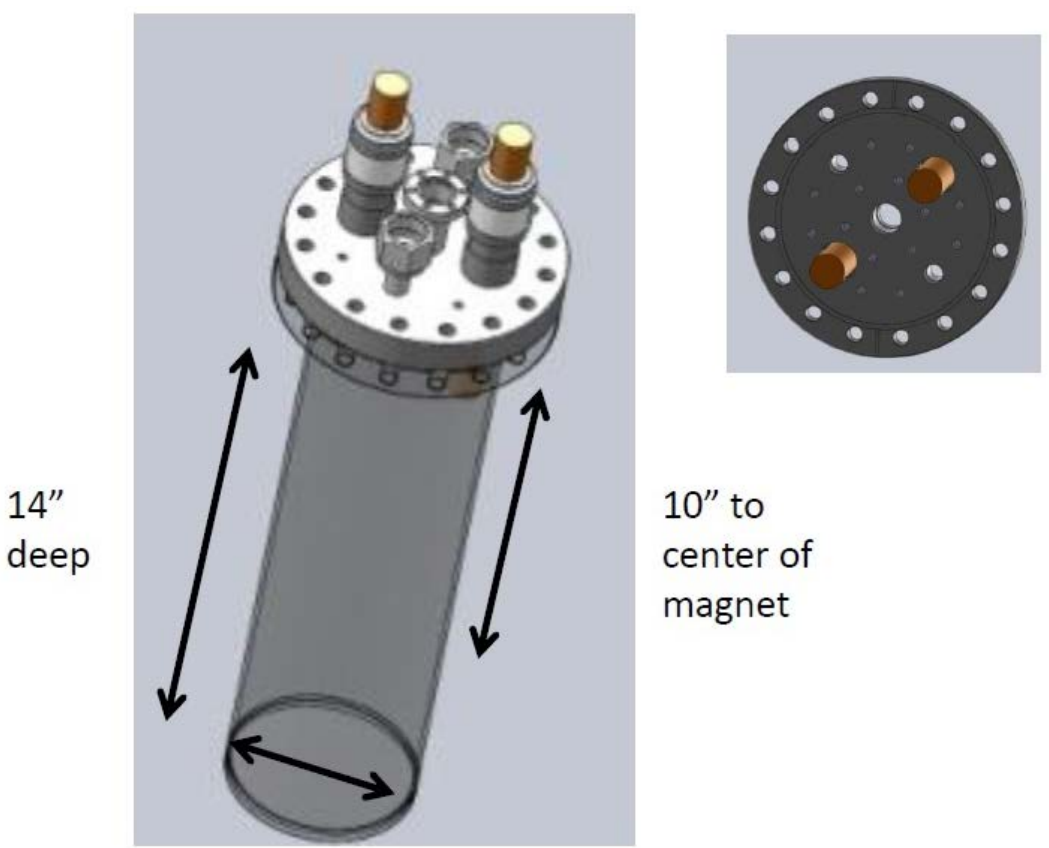

$3.75^{\prime \prime}$ ID

Fig. 13 Sample chamber and lid dimensions 


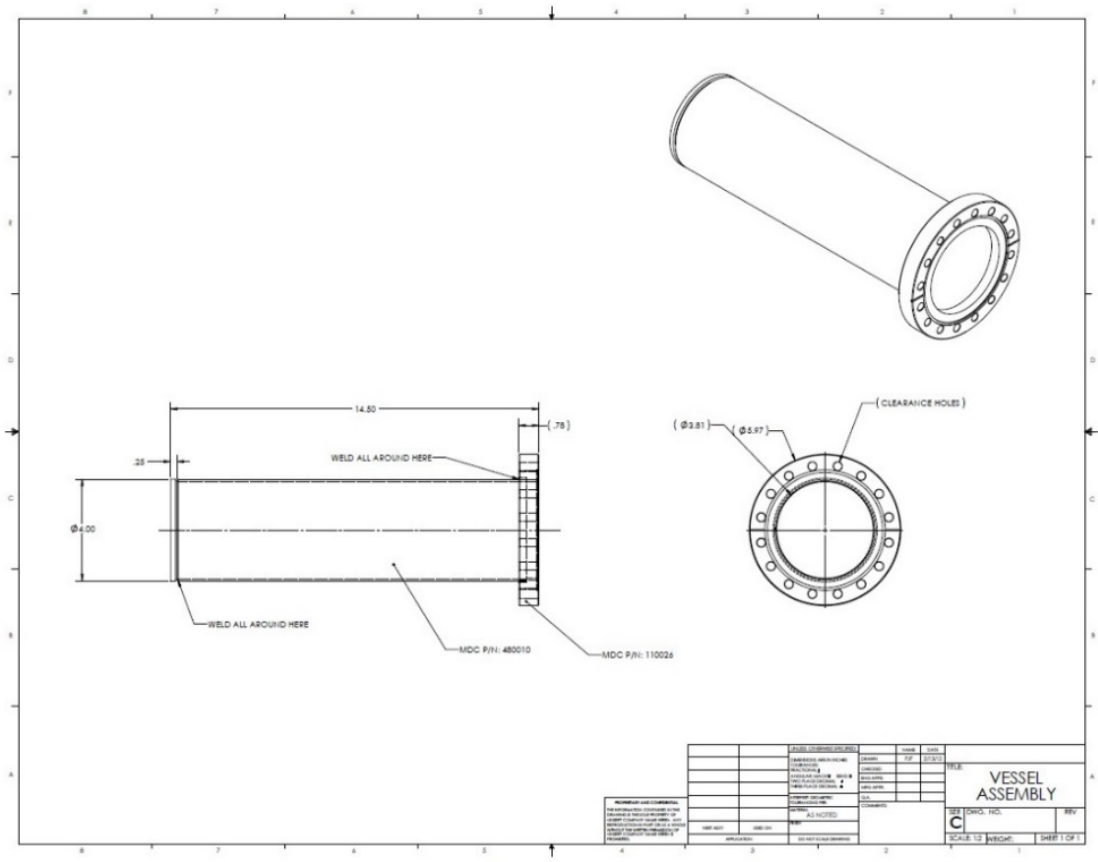

Fig. 14 Drawing of the sample chamber

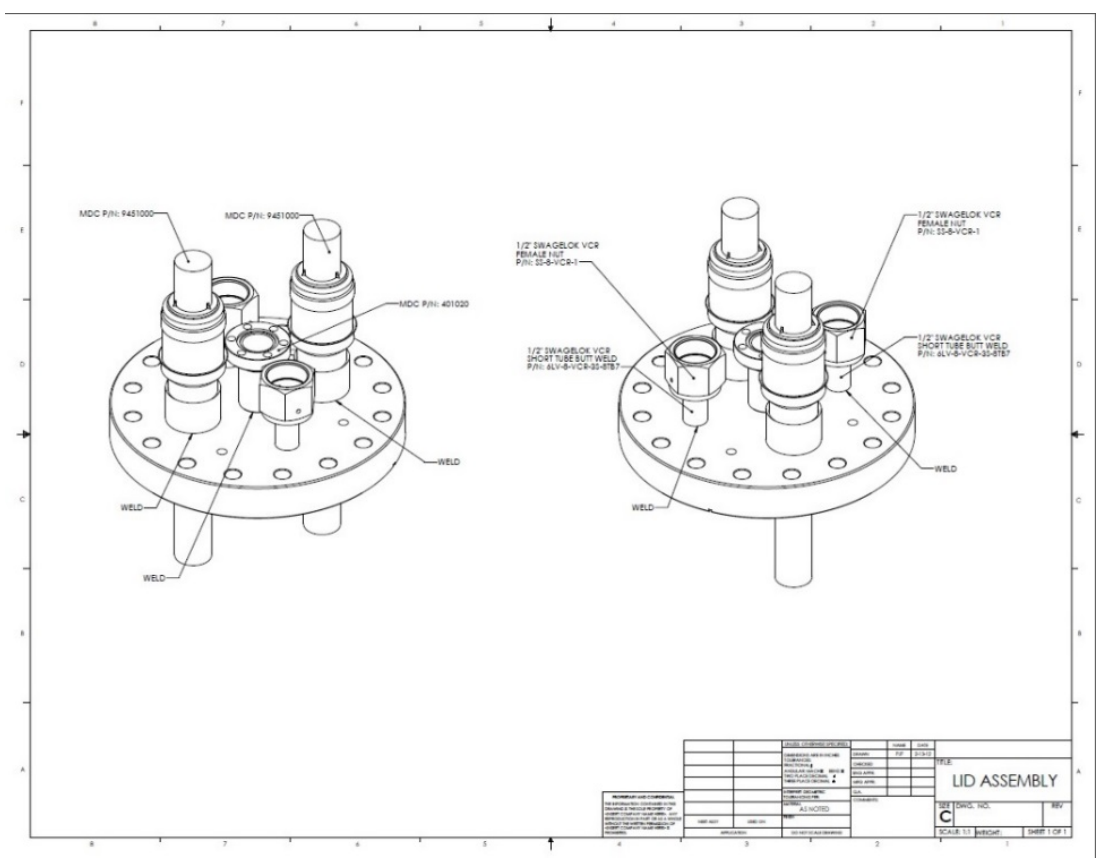

Fig. 15 Drawing of the sample chamber lid assembly 


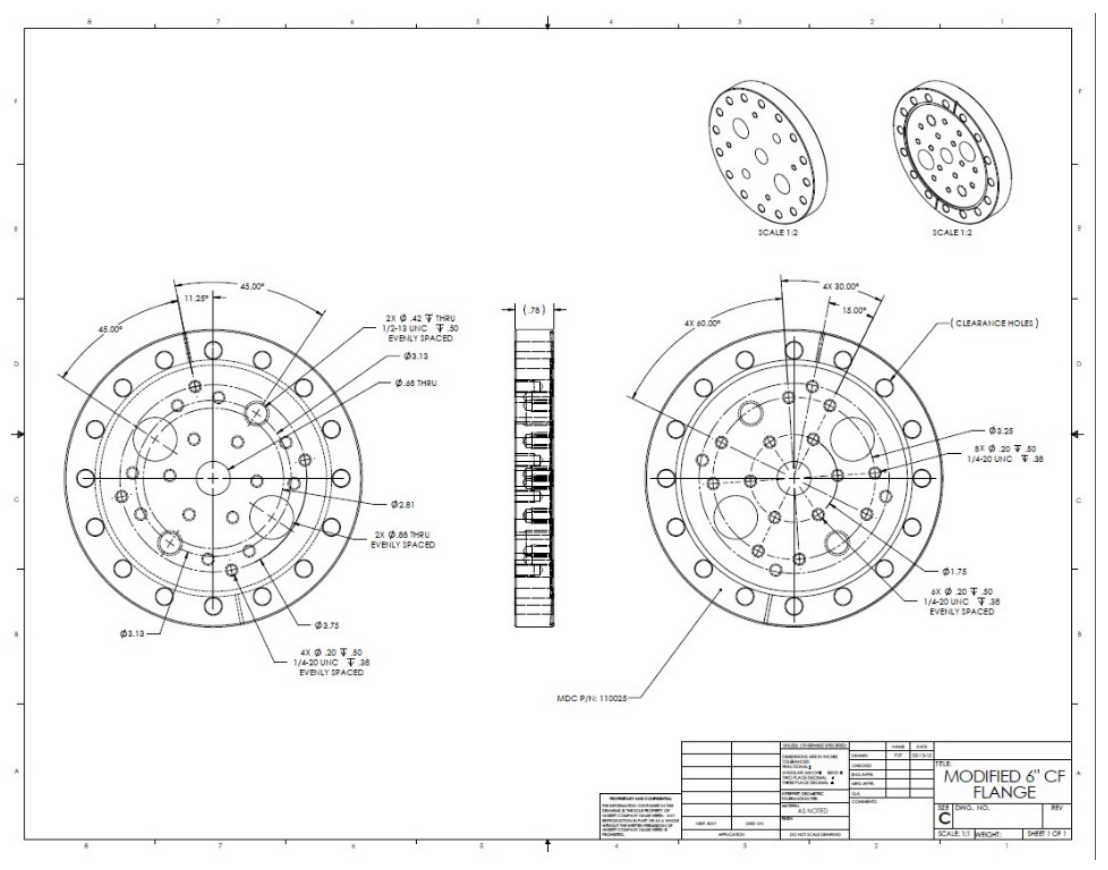

Fig. 16 Drawing of the flange to hold the superconducting coil assembly

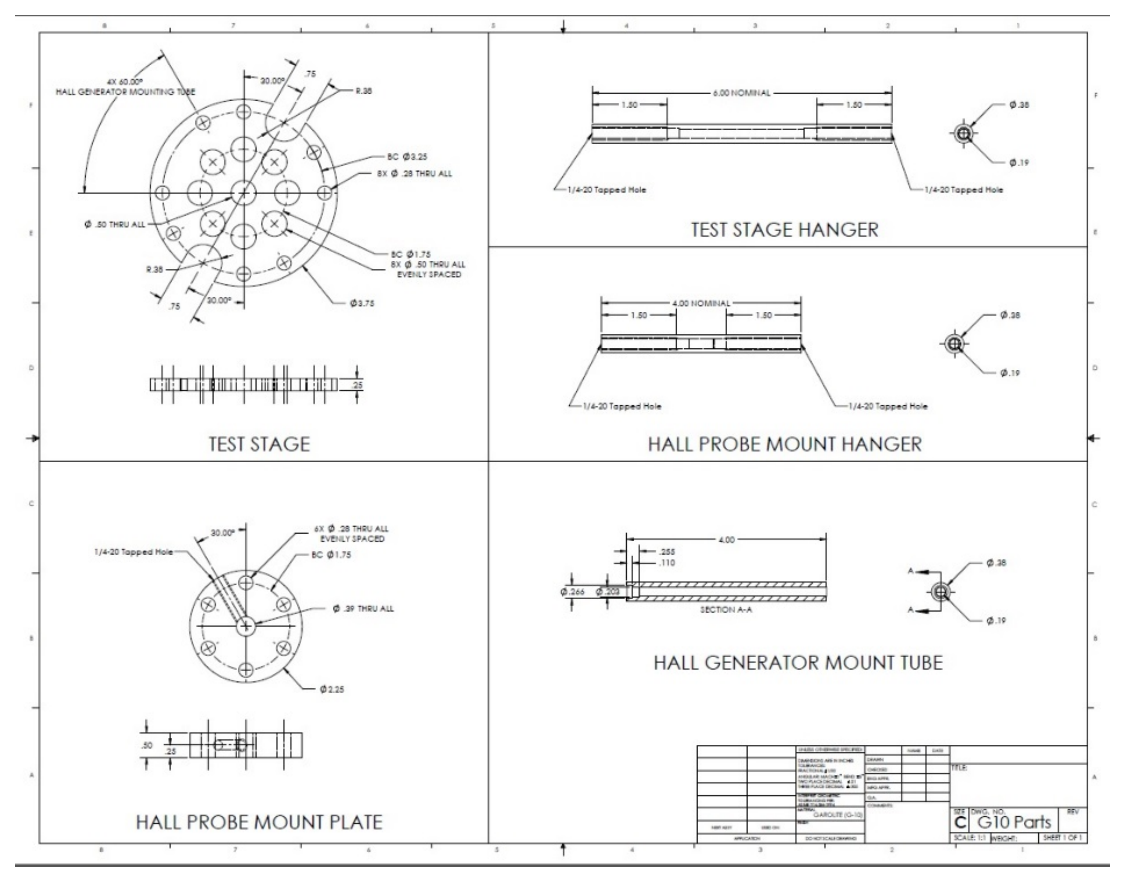

Fig. 17 Drawing of the bottom plate to hold the superconducting coil assembly 


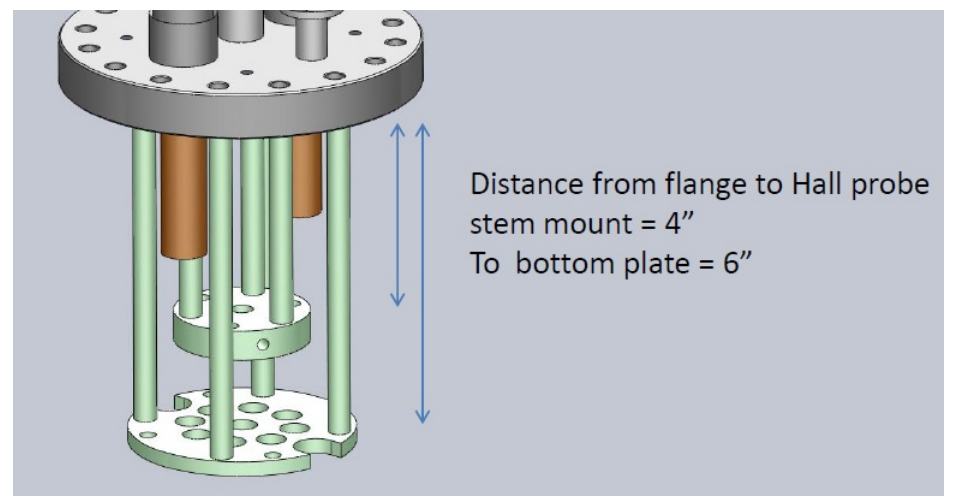

Fig. 18 Drawing of the fixture of the bottom plate and flange made of G10 materials with 4 rods attached to the bottom plate and the chamber lid. The flange is connected to the chamber lid with three G10 rods. The superconducting coil assembly is placed on the bottom plate.

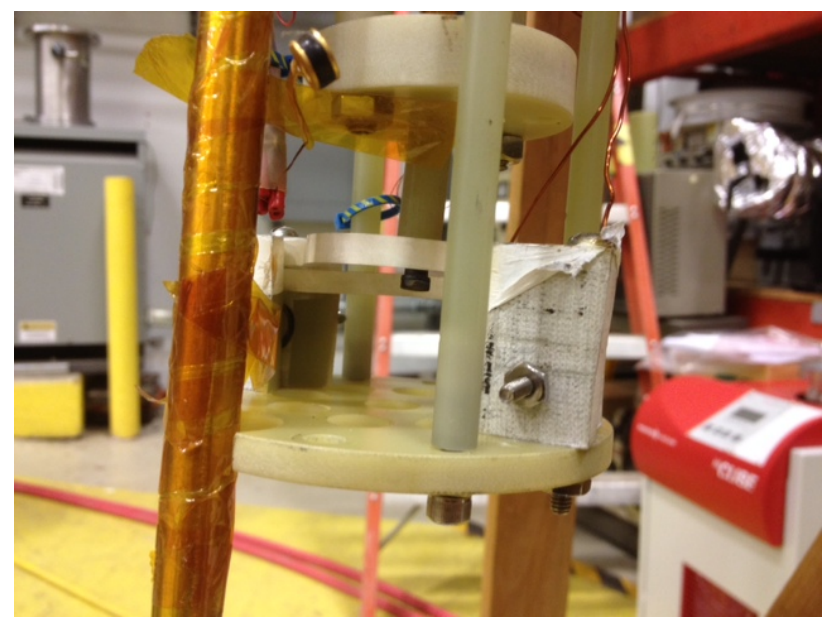

Fig. 19 The location of the Hall sensor inside the superconducting coil assembly

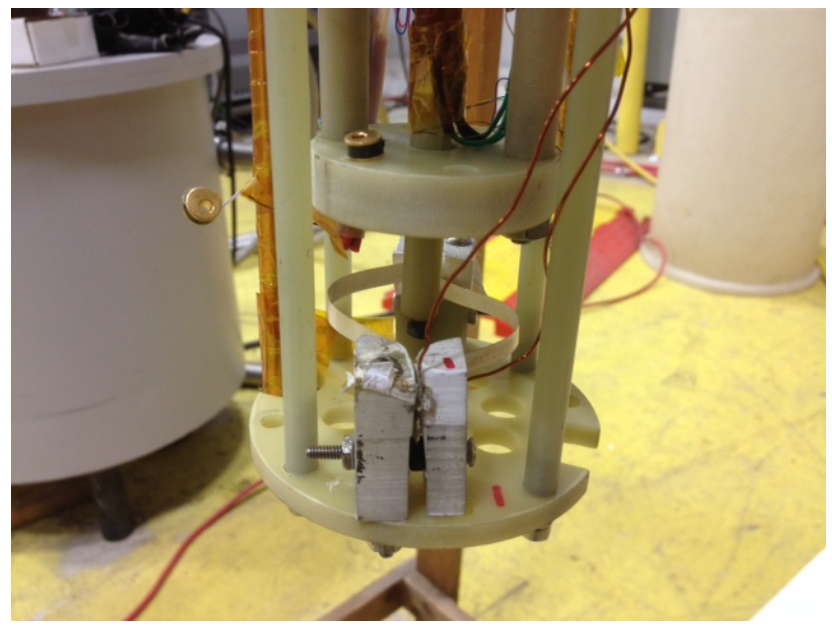

Fig. 20 Calibration of superconducting coil assembly electric current and magnetic field reading. The closed loop of the tape was cut at 1 end of the tape resulting in terminals that were soldered to 2 pieces of copper wire that were connected to the external power supply. 


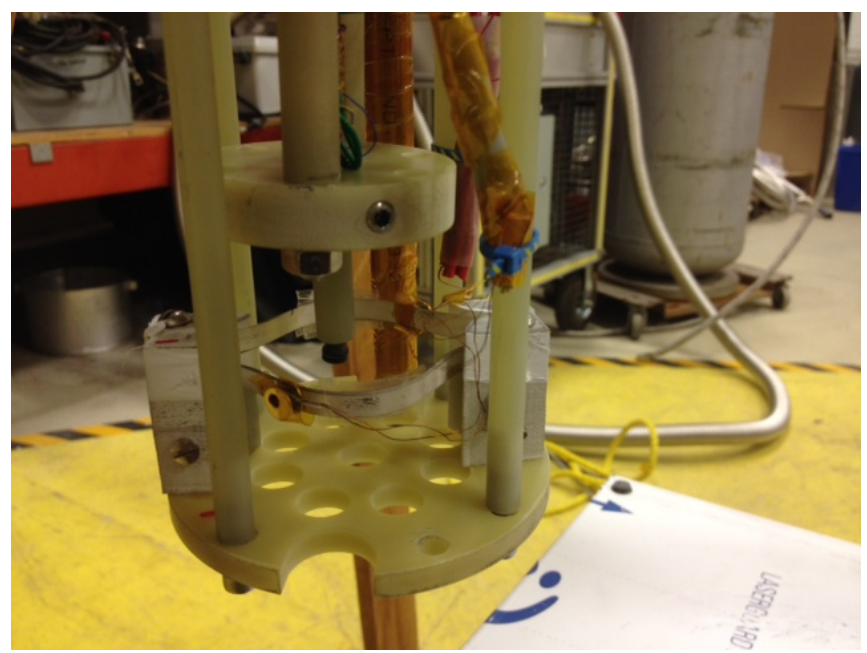

Fig. 21 The superconducting coil assembly placed on the bottom plate by the holder parts with the Hall sensor in the center of the coil assembly. The location is basically the same as Fig. 18. Toward to the left end of the loop, a temperature sensor was attached to the loop.

\section{Representative Results}

Figure 22 shows the data obtained when the coil was connected directly to the external power supply with current (A), voltage (V), and field (Gauss) versus time in operation in seconds at room temperature. A linear relationship was established, as shown in Fig. 23, between field and current in the coil. With this relationship, while in persistent current mode the actual persistent current level can be calculated from the gauss reading.

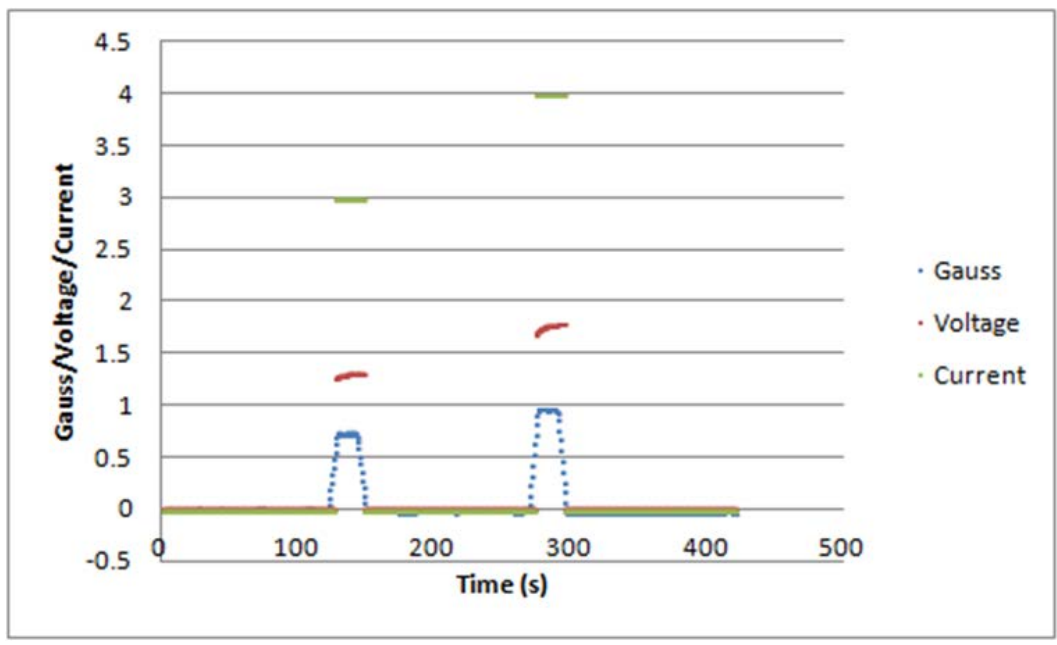

Fig. 22 Field readings in gauss at constant current in ampere at room temperature with the opened tape coil connected the leads of power supply 


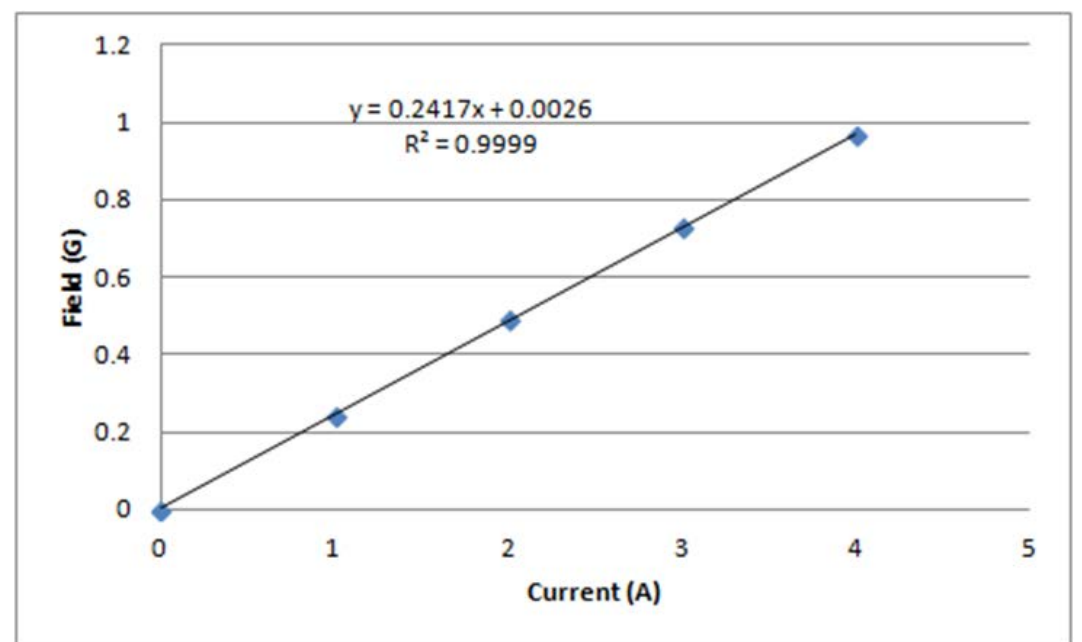

Fig. 23 Relationship of the field and electric current in the opened coil from the data in Fig. 22

\section{Discussion}

The main experimental results were reported and discussed in previous reports; ${ }^{10,11}$ here only a few issues related to the experimental aspects are briefly discussed. Although the size of the coil is basically determined by the available space of the cryostat, it is possible to have many pieces of the tape cut in the same size and stacked together so that a much higher level of total supercurrent could be generated, and a much higher magnetic field, as well. The support holder parts for the coil assembly have not been optimized for the experiment, and a single piece of the holder is now envisioned for future similar experiments, with which the position of the coil assembly could be precisely controlled. The structure and materials of the holder parts should also be considered in relation to the ability to withstand the induced Lorentz forces, especially in the cases of higher supercurrent and higher magnetic field, such as in trapped field magnet (TFM) experiment using pulsed activation. One unknown aspect is the variation of the coils' position with temperature from room to cryogenic. A better design of the coils assembly holder with proper structure and materials will be the key to addressing the above issues and concerns in future work. 


\section{Conclusion}

The experimental setup and the protocol worked out well during several months from October 2014 to March 2015. A few key points worthwhile mentioning are as follows:

1) All the electric connections had to be well tested before experiment to ensure no electric shortage occurred.

2) The time and field signals, or any other properties to be recorded, should be well synchronized for correct data acquisition.

3) The cryostat temperature has to be fully equilibrated and stabilized before data acquisition.

This report provides information to re-setup the equipment(s) for future similar experiments. This line of investigation on the performance of commercial coated conductors is much needed to contribute to the highly desirable knowledge base on which the superconducting technology could be developed to a higher level in the context of a holistic multidisciplinary enlightened empirical approach. ${ }^{13}$ 


\section{References}

1. Zhang Y, Lehner TF, Fukushima T, Sakamoto H, Hazelton DW. Progress in production and performance of second generation (2G) HTS wire for practical applications. IEEE Trans. Appl. Supercond. 2014;24:7500405.

2. Fleshler S, DeMoranville K, Gannon Jr J, Li X, Podtburg E, Rupich MW, Sathyamurthy S, Thieme CLH, Tucker D, Whitman L. Development status of AMSC amperium ${ }^{\circledR}$ wire. J. Phys: Conf. Series 2014;507:022005.

3. Lee S, Petrykin V, Molodyk A, Samoilenkov S, Kaul A, Vavilov A, Vysotsky V, Fetisov S. Development and production of second generation high Tc superconducting tapes at SuperOx and first tests of model cables. Supercond. Sci. Technol. 2014;27:044022.

4. Haugan T, Barnes PN, Wheeler R, Meisenkothen F, Sumption M. Addition of nanoparticle dispersions to enhance flux pinning of the $\mathrm{YBa} 2 \mathrm{Cu} 3 \mathrm{O} 7-\mathrm{x}$ superconductor. Nature. 2004;430:867-870.

5. Mele P, Guzman R, Gazquez J, Puig T, Obradors X, Saini S, Yoshida Y, Mukaida M, Ichinose A, Matsumoto K, Adam MI High pinning performance of $\mathrm{YBa} 2 \mathrm{Cu} 3 \mathrm{O} 7-\mathrm{x}$ films added with $\mathrm{Y} 2 \mathrm{O} 3$ nanoparticulate defects. Supercond. Sci. Technol. 2015;28:024002.

6. Selvamanickam V, Heydari GM, Xu A, Galstyan E, Delgado L, Cantoni C. High critical currents in heavily doped (Gd,Y)Ba2Cu3Ox superconductor tapes. Appl. Phys. Lett. 2015;106:032601.

7. Maeda H, Yanagisawa Y. Recent developments in high-temperature superconducting magnet technology. IEEE Trans. Appl. Supercond. 2014;24:4602412.

8. Obradors X, Puig T. Coated conductors for power applications: materials challenges Supercond. Sci. Technol. 2014;27:120501.

9. Levin GA, Barnes PN, Murphy J, Brunke L,Long JD, Horwath J, and Turgut Z. Persistent current in coils made out of second generation high temperature superconductor wire. Appl. Phys. Lett. 2008;93:062504.

10. Rong CC, Barnes PN, Levin GA, Miller JD, Santosusso DJ, Fitzpatrick BK. Investigation of the relaxation of persistent current in superconducting closed loops made out of YBCO coated conductors. IEEE Trans. Appl. Supercond. 2015;25:8200805. 
11. Rong CC, Miller JD, Levin GA, Barnes PN. Investigation of persistent current characteristics of closed loops of YBCO coated conductors. Supercond. Sci. Technol. In preparation,2015.

12. Lakeshore Cryotronics, Inc, Form F010-03-00 - Revision C, Page 7, May 2014.

13. Chu CW. A possible approach from BCS through HTS to RTS with three examples. Physica C 2012;482:33-44. 


\begin{tabular}{|c|c|}
\hline $\begin{array}{c}1 \\
(\mathrm{PDF})\end{array}$ & $\begin{array}{l}\text { DEFENSE TECHNICAL } \\
\text { INFORMATION CTR } \\
\text { DTIC OCA }\end{array}$ \\
\hline $\begin{array}{c}2 \\
(\mathrm{PDF})\end{array}$ & $\begin{array}{l}\text { DIRECTOR } \\
\text { US ARMY RESEARCH LAB } \\
\text { RDRL CIO LL } \\
\text { IMAL HRA MAIL \& RECORDS } \\
\text { MGMT }\end{array}$ \\
\hline $\begin{array}{c}1 \\
(\mathrm{PDF})\end{array}$ & $\begin{array}{l}\text { GOVT PRINTG OFC } \\
\text { A MALHOTRA }\end{array}$ \\
\hline $\begin{array}{c}2 \\
(\mathrm{PDF})\end{array}$ & $\begin{array}{l}\text { US ARMY RESEARCH LAB } \\
\text { RDRL SED E } \\
\text { CHARLES C RONG } \\
\text { PAUL N BARNES }\end{array}$ \\
\hline $\begin{array}{c}1 \\
(\mathrm{PDF})\end{array}$ & $\begin{array}{l}\text { NAVAL SURFACE WARFARE CTR } \\
\text { CARDEROCK DIV } \\
\text { JASON D MILLER }\end{array}$ \\
\hline $\begin{array}{c}1 \\
(\mathrm{PDF})\end{array}$ & $\begin{array}{l}\text { FLORIDA INSTITUTE OF TECHNOLOGY } \\
\text { GEORGE A LEVIN }\end{array}$ \\
\hline
\end{tabular}

